\title{
Nocturia in patients with cognitive dysfunction: a systematic review of the literature
}

Rebecca Haddad ${ }^{1,2^{*}+}$ (D) Thomas F. Monaghan ${ }^{1,3+}$, Charles Joussain ${ }^{4,5}$, Véronique Phé ${ }^{6}$, Wendy Bower ${ }^{7}$, Saskia Roggeman ${ }^{1}$, Gilberte Robain ${ }^{2}$ and Karel Everaert ${ }^{1}$

\begin{abstract}
Background: The objective of this study is to evaluate current literature on the association between cognitive dysfunction and nocturia.

Methods: A systematic review following Preferred Reporting Items for Systematic Reviews and Meta-Analyses (PRISMA) statement was conducted through MEDLINE, EMBASE and COCHRANE databases and completed in November 2019. Randomized and non-randomized studies were included if they assessed the association between cognitive dysfunction and nocturia in older participants with or without neurological diseases. The quality of included studies was evaluated using the Risk of Bias Assessment tool for Non-randomized Studies (RoBANS).

Results: A total of 8 cross-sectional studies conducted in older patient populations met the criteria for inclusion. A statistically significant association was identified in 6 studies on univariate analysis, which persisted in 2 studies after controlling for confounding factors. The association between cognitive dysfunction and nocturia was positive for all 6 significant analyses. The overall risk of bias was unclear.

Conclusion: A significant positive association between cognitive dysfunction and nocturia was identified. However, research has been limited to cross-sectional studies, which precludes identification of causality between cognitive dysfunction and nocturia. Heightened awareness of the complex interplay between cognition and nocturia would allow professionals involved in the care of cognitively impaired patients with concomitant nocturia to more effectively manage these symptoms.
\end{abstract}

Keywords: Nocturia, Lower urinary tract symptoms, Cognitive dysfunction, Systematic review, Epidemiology

\footnotetext{
* Correspondence: rebecca.haddad@aphp.fr

${ }^{\dagger}$ Rebecca Haddad and Thomas F. Monaghan contributed equally to this work.

'Department of Urology, Ghent University Hospital, Corneel Heymanslaan 10, 9000 Ghent, Belgium

${ }^{2}$ GRC 001 GREEN Neuro-Urology Research Group, Sorbonne Université Rothschild Academic Hospital AP-HP, F-75012 Paris, France

Full list of author information is available at the end of the article
}

(c) The Author(s). 2020 Open Access This article is licensed under a Creative Commons Attribution 4.0 International License, which permits use, sharing, adaptation, distribution and reproduction in any medium or format, as long as you give appropriate credit to the original author(s) and the source, provide a link to the Creative Commons licence, and indicate if changes were made. The images or other third party material in this article are included in the article's Creative Commons licence, unless indicated otherwise in a credit line to the material. If material is not included in the article's Creative Commons licence and your intended use is not permitted by statutory regulation or exceeds the permitted use, you will need to obtain permission directly from the copyright holder. To view a copy of this licence, visit http://creativecommons.org/licenses/by/4.0/. The Creative Commons Public Domain Dedication waiver (http://creativecommons.org/publicdomain/zero/1.0/) applies to the data made available in this article, unless otherwise stated in a credit line to the data. 


\section{Background}

Nocturia, defined as the act of waking to void during the hours of intended sleep, is among the most common and bothersome lower urinary tract symptoms (LUTS) $[1,2]$. Although nocturia is a pervasive complaint across different patient populations, older people are disproportionally affected, with clinically-significant symptoms reported in up to $60 \%$ of patients over 70 years of age [3]. Nocturia has been associated with significant morbidity and mortality [4] and shown to have a direct adverse effect on sleep architecture [5, 6]. Among older patient populations, nocturia confers an increased risk of both falls and hip fractures $[7,8]$, and it stands to reason that this effect may be more pronounced in the setting of concomitant cognitive impairment [9].

Notably, there exists a robust association between cognitive dysfunction - which refers to deficits in attention, verbal and nonverbal learning, short-term and working memory, visual and auditory processing, problem solving, processing speed, motor functioning - and other LUTS, particularly urinary incontinence [10-12]. Moreover, current literature has identified a diverse array of risk factors common to both nocturia and cognitive dysfunction, including aging, comorbidities [13], brain lesions - particularly those affecting the hypothalamicpituitary axis [14], and sleep disturbances [15]. However, relative to other LUTS, the relationship between nocturia and cognitive dysfunction remains poorly characterized. Increased awareness of the complex interplay between cognition and nocturia would facilitate the evaluation and management of cognitively impaired patients with concomitant nocturia.

The objective of this systematic review was to evaluate available evidence on the association between cognitive dysfunction and nocturia.

\section{Methods}

This systematic review was conducted according to the Preferred Reporting Items for Systematic Reviews and Meta-Analyses (PRISMA) statement [16].

\section{Eligibility criteria \\ Types of studies}

Original studies including randomized controlled trials (RCTs), non-RCTs, single-arm cohort studies, casecontrol studies, cross-sectional studies, and case series were included. Review articles and meta-analyses were not included, but references from these studies were reviewed, and eligible articles were subsequently retrieved.

\section{Population}

Only studies involving adults were selected. No limits on gender, ethnicity or setting were applied. The presence of nocturia had to have been reported in participants, regardless of the method of assessment or the threshold used to define nocturia. Cognitive dysfunction had to have been assessed by either a validated neuropsychological test or defined via formal diagnosis of a neurocognitive disorder.

\section{Outcomes}

The primary outcome was the association between cognitive dysfunction with neurodegenerative disorders of aging and nocturia. Measurement of this association was specified by an effect size indicator and/or a statistical significance level.

\section{Search strategy and information sources}

The MEDLINE, EMBASE, COCHRANE and CENTRAL databases were used with specific keywords (MeSH or Emtree terms) combined with Boolean operators. The complete search strategy is available as supplementary data (Additional File 1). The search was completed in November 2019 and no date limits were applied. No limit of language was applied. References cited in systematic reviews or meta-analyses were searched. Once key articles were identified, additional searches were performed on PubMed using the "Related Articles" search feature.

\section{Data collection and analysis Study selection}

Two review authors (RH \& TM) independently screened the titles and abstracts yielded by the search after inclusion criteria had been applied. Full articles were obtained for all titles that appeared to meet the inclusion criteria or for which there was any uncertainty. Review authors then screened the complete articles and independently determined whether these met the inclusion criteria. Disagreement was resolved through discussion. Rationale for excluding trials was recorded. Figure 1 summarizes this selection process according to the PRISMA statement.

\section{Data extraction}

Duplicate data were extracted independently ( $\mathrm{RH}$ \& TM) using a standard spreadsheet, which captured information on study design, population, and the association between cognitive dysfunction and nocturia. A summary is provided in the results section (Tables $1 \& 2$ ).

\section{Assessment of the risk of bias in individual studies}

The quality of non-randomized studies was assessed using the validated Risk of Bias Assessment tool for Non-randomized Studies (RoBANS) [24]. Dispositions were made independently by two authors (RH \& TM). Disagreements were resolved first by discussion, and 


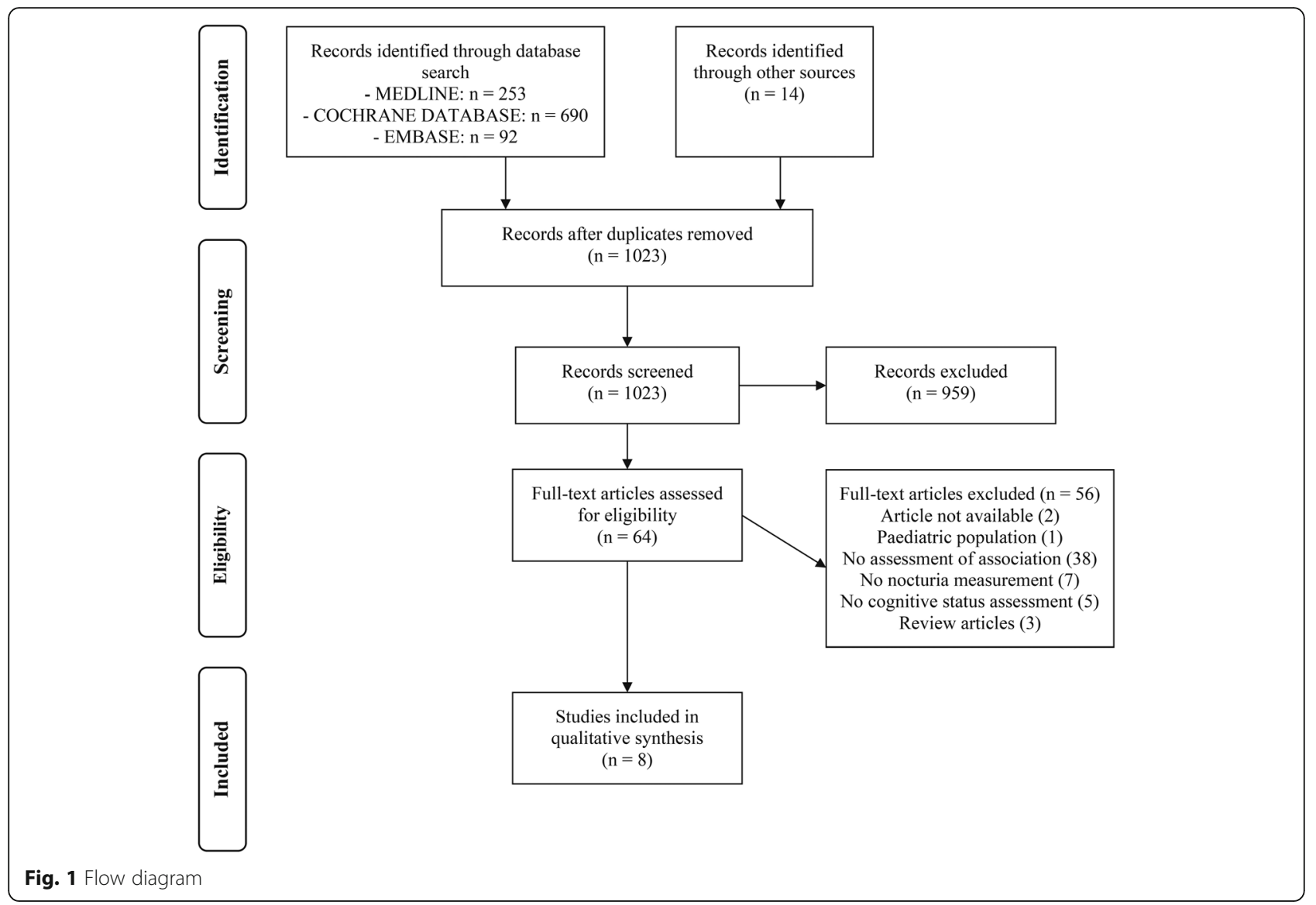

then by consulting a third author for arbitration as warranted (KE). A summary is provided in the results section (Fig. 2).

\section{Results}

\section{Study selection}

A flowchart of the database search and selection process is provided in Fig. 1. Of the 1023 non-duplicate articles identified from the databases, 64 articles were eligible for systematic review. A total of 8 studies were included in the final analysis.

\section{Study characteristics}

Study characteristics are summarized in Table 1 . The 8 studies included all featured a cross-sectional study design and community-dwelling participants. Four studies specifically enrolled older patients [17, 21-23], 3 studies [18-20] were conducted in Parkinson's disease (PD) patients and 1 enrolled participants with probable Alzheimer's disease (AD) [11]. Cognitive dysfunction was assessed by Mini-Mental State Examination (MMSE) in 6 studies [11, 17, 20-23], and also the Clinical Dementia Rating (CDR) scale in 1of these studies [11]. The Montreal Cognitive Assessment was used in 1 study [18], and a specific validated scale for impulsivity in PD in 1 study
[19]. The prevalence of cognitive dysfunction ranged from 4 to $58 \%$ in the studies which reported this parameter $[17,18,23]$. Nocturia was defined as self-reported awakening from sleep to pass urine 2 or more times per night [21-23], or without any definite threshold [11, 17] or by symptom questionnaires [18-20]. Overall, nocturia was reported in 19 to $61 \%$ of study participants $[17,20]$.

\section{Assessment of the association between cognitive dysfunction and nocturia}

The association between cognitive dysfunction and nocturia was statistically significant in 6 studies [11, 17, 18, 21-23], all in the same direction (Table 2). In 1 study [18], nocturia was more frequently identified in PD patients with cognitive dysfunction compared to those without (56\% vs. $37 \%$ respectively). In 4 other studies [17, 21-23], a higher MMSE score was a protective factor for nocturia, whereas Jung et al. (2017) did not find any correlation between MMSE score and nocturia in patients with probable AD. Lee et al. (2012) determined that a higher MMSE score was an independent protective factor after adjustment for multiple potential confounders (OR 0.6, 95\% CI [0.5-0.9], $p=$ 0.006). In the study by Zhang et al. (2016), this association was independent in multivariable analysis (OR 1.7, 95\%CI [1.1-2.8], $p=0.03)$, but it should be noted that the group 
Table 1 Study characteristics

\begin{tabular}{|c|c|c|c|}
\hline Study & Population & Nocturia Assessment & Cognitive dysfunction Assessment \\
\hline Dutoglu et al. (2019) [17] & $\begin{array}{l}858 \text { outpatients admitted to a } \\
\text { geriatric center } \\
\text { Female: } 100 \% \\
\text { Mean (sd) age: } 74.1 \text { (8.2) years }\end{array}$ & $\begin{array}{l}\text { "Generally, during the past } \\
30 \text { days, how many times do you } \\
\text { usually urinate after you have gone } \\
\text { to sleep at night until the time you } \\
\text { got up in the morning?" } \\
\text { Cut-off: } 1,2,3,4 \text { or more } \\
\text { Prevalence: 19.0, 24.2, 18.4, and } 24.1 \% \\
\text { respectively }\end{array}$ & $\begin{array}{l}\text { MMSE and Dementia diagnosed } \\
\text { using the DSM V } \\
\text { Mean (sd) MMSE score: } 24.7(4.9), \\
25.0 \text { (4.2), } 24.9 \text { (3.7), } 24.2(4.4), 23.9 \text { (4.9) } \\
\text { in patients with 0, } 1,2,3 \text { or } \geq 4 \text { nocturia } \\
\text { episodes respectively } \\
\text { Prevalence (dementia): } 4.4 \%\end{array}$ \\
\hline Jung et al. (2017) [11] & $\begin{array}{l}376 \text { patients with probable } \\
\text { Alzheimer's disease } \\
\text { Female: } 51.1 \% \\
\text { Age range: } 56-92 \text { years }\end{array}$ & $\begin{array}{l}\text { OABSS } \\
\text { Mean }(\mathrm{sd}) \text { number of nocturia episodes: } \\
1.2(0.8), 1.2(0.9) \text { and } 1.6(1.0) \text { in patients } \\
\text { with OABSS } \leq 5,6-11 \text { or } \geq 12 \text { respectively } \\
\text { Prevalence: NR }\end{array}$ & $\begin{array}{l}\text { MMSE and CDR scale } \\
\text { Mean (sd) MMSE score: } 14.4(7.6) \text { in } \\
\text { patients with OAB } \\
\text { Mean (sd) CDR score: } 2.3(0.9) \text { in } \\
\text { patients with OAB }\end{array}$ \\
\hline Zhang et al. (2016) [18] & $\begin{array}{l}454 \text { patients with Parkinson's } \\
\text { disease } \\
\text { Female: } 42.7 \% \\
\text { Mean (sd) age: } 61.5 \text { (10.9) years }\end{array}$ & $\begin{array}{l}\text { NMSS } \\
\text { Mean (sd) NMSS score for nocturia: } \\
\text { 2.4 (3.3) } \\
\text { Cut-off: NR } \\
\text { Prevalence: } 47.2 \%\end{array}$ & $\begin{array}{l}\text { MoCA } \\
\text { Mean (sd) MoCA score: } 23.7 \text { (4.5) } \\
\text { Prevalence (MoCA } \leq 25): 58.1 \%\end{array}$ \\
\hline Scullin et al. (2013) [19] & $\begin{array}{l}143 \text { patients with Parkinson's } \\
\text { disease } \\
\text { Female: } 35 \% \\
\text { Mean (sd) age: } 64.7 \text { (9.0) years }\end{array}$ & $\begin{array}{l}\text { "When you awaken during the night, } \\
\text { how often do you urinate?" on sleep } \\
\text { questionnaire drawn from existing } \\
\text { studies; Nocturia frequency evaluated } \\
\text { on 4-point Likert scale ( } 1 \text { = "never," } \\
4 \text { = "very often") } \\
\text { Prevalence: NR }\end{array}$ & $\begin{array}{l}\text { Impulsivity determined by at least } 1 \\
\text { "yes" to the Minnesota Impulse Disorder } \\
\text { Interview (MIDI) questions } \\
\text { Prevalence: } 26.6 \%\end{array}$ \\
\hline Vaughan et al. (2013) [20] & $\begin{array}{l}63 \text { patients with Parkinson's } \\
\text { disease } \\
\text { Female: } 35 \% \\
\text { Mean (sd) age: } 63 \text { (9.7) years }\end{array}$ & $\begin{array}{l}\text { IPSS } \\
\text { Cut-off: } \geq 2 \text { voids/nights } \\
\text { Prevalence: } 61 \%\end{array}$ & $\begin{array}{l}\text { MMSE } \\
\text { Mean (sd) MMSE score: } 28.6(1.5) \text { in } \\
\text { patients without nocturia and } 28.5 \\
\text { (1.9) in patients without } \\
\text { Prevalence: NR }\end{array}$ \\
\hline Galizia et al. (2012) [21] & $\begin{array}{l}1288 \text { community-dwelling } \\
\text { individuals } \\
\text { Female: } 57 \% \\
\text { Mean (sd) age: } 74.2 \text { (6.3) years }\end{array}$ & $\begin{array}{l}\text { History taking } \\
\text { Cut-off: } \geq 2 \text { voids/nights } \\
\text { Prevalence: } 45.8 \%\end{array}$ & $\begin{array}{l}\text { MMSE } \\
\text { Mean (sd) MMSE score: } 25.3 \text { (4.8) } \\
\text { Prevalence: NR }\end{array}$ \\
\hline Lee et al. (2012) [22] & $\begin{array}{l}299 \text { community-dwelling men } \\
\text { Mean (sd) age: } 71.2(5.0) \text { years }\end{array}$ & $\begin{array}{l}\text { History taking } \\
\text { Cut-off: } \geq 2 \text { voids/nights } \\
\text { Prevalence: } 56.0 \%\end{array}$ & $\begin{array}{l}\text { MMSE } \\
\text { Mean (sd) MMSE score: } 25.6 \text { (3.4) } \\
\text { Prevalence: NR }\end{array}$ \\
\hline Burgio et al. (2010) [23] & $\begin{array}{l}1000 \text { Medicare beneficiaries } \\
\text { Female: } 50 \% \\
\text { Mean (sd) age: } 73.8 \text { (NR) years }\end{array}$ & $\begin{array}{l}\text { History taking } \\
\text { Cut-off: } \geq 2 \text { voids/nights } \\
\text { Prevalence: } 58.5 \%\end{array}$ & $\begin{array}{l}\text { MMSE } \\
\text { Mean (sd) MMSE score: } 25 \text { (4.9) } \\
\text { Prevalence (MMSE < 24): } 29.8 \%\end{array}$ \\
\hline
\end{tabular}

BPH Benign prostatic hypertrophy, CI Confidence interval, CDR Clinical Dementia Rating; DSM Diagnostic and Statistical Manual of Mental Disorders, HAMA Hamilton Anxiety Rating Scale, HAMD Hamilton Depression Rating Scale, IPSS International Prostate Symptom Score, MoCA Montreal Cognitive Assessment, MMSE Mini-Mental State Examination, NMSS Non-Motor Symptom Scale, NR Not reported, OABSS Overactive Bladder Symptom Score, OR Odds ratio, $r$ Correlation coefficient, sd Standard deviation, UPDRS Unified Parkinson's Disease Rating Scale

studied the entire urinary domain (including nocturia) of the Non-Motor Symptoms Scale (opposed to nocturia as a standalone entity). Minimal clinically important difference in cognitive scores was reached in two of the three studies where assessment was possible $[17,22]$.

\section{Risk of bias in included studies}

The risk of biases is summarized in Fig. 2. Regarding the selection of participants, the risk of bias was unclear in all studies, since no criteria could be applied to cross sectional studies using the RoBANS instrument. Nevertheless, 3 studies [21-23] randomly selected their participants, with a response rate ranging from 75 to $98 \%$. Of the 8 studies included, only 3 controlled their analyses for confounding factors [18, 22, 23]. Potential confounding factors considered included age (in all of these studies), ethnicity [23], gender [18], education (in all of these studies), PD history (age of onset, disease severity assessed by the Unified PD Rating Scale, hallucination or gastrointestinal symptoms) in the study by Zhang et al. (2016), urological history (transitional volume zone, history of benign prostate hyperplasia, alpha blockers intake) in the study by Lee et al. (2012) and comorbidities such as sleep or fatigue symptoms [18], lower limbs edema, hypertension, obesity or urinary incontinence [23], depression [18, 22] and anxiety [18]. When gender was not considered, analyses were stratified according to it. All but 1 of the studies [23] were deemed to be at low 
Table 2 Association between cognitive dysfunction and nocturia

\begin{tabular}{|c|c|c|}
\hline Study & Univariate analysis & Multivariable analysis \\
\hline Dutoglu et al. (2019) [17] & $\begin{array}{l}\text { Lower MMSE scores in patients with } \geq 2 \text { nocturia episodes } \\
\text { compared to those with }<2 \text { episodes; MCID observed only } \\
\text { for the group with at least } 4 \text { nocturnal voids compared to } \\
\text { the group with } 1 \text { nocturnal void } \\
\text { No difference in dementia prevalence }\end{array}$ & Not performed \\
\hline Jung et al. (2017) [11] & $\begin{array}{l}\text { No significant correlation between nocturia and MMSE } \\
\text { Significant correlation between nocturia and CDR scale: } \\
r=0.23 \text {; MCID: not assessable }\end{array}$ & Not performed \\
\hline Zhang et al. (2016) [18] & $\begin{array}{l}\text { Significant difference of nocturia prevalence in patients } \\
\text { with cognitive dysfunction vs. without } 56.3 \% \text { vs. } 36.8 \% \text {. } \\
\text { Mean (sd) NMSS nocturia sub-score significantly higher } \\
\text { in patients with cognitive dysfunction vs. without } 2.9 \text { (3.4) } \\
\text { vs. } 1.7 \text { (3.0); MCID: not assessable }\end{array}$ & $\begin{array}{l}\text { Urinary disorders (including nocturia) as a } \\
\text { significant risk factor for cognitive dysfunction } \\
\text { OR } 1.7,95 \% \mathrm{Cl}[1.1-2.8]\end{array}$ \\
\hline Scullin et al. (2013) [19] & $\begin{array}{l}\text { No significant difference in Mean (sd) nocturia frequency } \\
\text { score in patients with impulsivity vs. without impulsivity }\end{array}$ & - \\
\hline Vaughan et al. (2013) [20] & $\begin{array}{l}\text { No significant difference in MMSE score in patients with } \\
\text { nocturia vs. without nocturia }\end{array}$ & - \\
\hline Galizia et al. (2012) [21] & $\begin{array}{l}\text { Mean (sd) MMSE score significantly lower in subjects with } \\
\text { vs. without nocturia in univariate analysis: } 25.0 \text { (5.2) vs. } 25.6 \\
\text { (4.4); MCID not reached }\end{array}$ & Not performed \\
\hline Lee et al. (2012) [22] & $\begin{array}{l}\text { Mean (sd) MMSE score significantly lower in subjects with } \\
\text { vs. without nocturia in univariate analysis: } 24.4(4.0) \text { vs. } \\
\text { 25.9(3.4); MCID reached }\end{array}$ & $\begin{array}{l}\text { Higher MMSE protective factor of nocturia }{ }^{b} \text { : } \\
\text { OR } 0.695 \% \mathrm{Cl}[0.5-0.9]\end{array}$ \\
\hline Burgio et al. (2010) [23] & $\begin{array}{l}\text { MMSE protective factor of nocturia with OR } 0.9 \\
\text { (CI non available) } \\
\text { MCID not assessable }\end{array}$ & Non-significant association ${ }^{c, d}$ \\
\hline
\end{tabular}

BPH Benign prostatic hypertrophy; $C I$ Confidence interval, $C D R$ Clinical dementia rating scale (MCID: 1-2 point increase indicative of a meaningful decline), HAMA Hamilton Anxiety Rating Scale, HAMD Hamilton Depression Rating Scale, MCID Minimal clinically important difference, MMSE Mini-Mental State Examination (MCID: 1-3 point decrease indicative of a meaningful decline), NMSS Non-Motor Symptom Scale (MCID: 13.91 point increase indicative of a meaningful change), OR Odds ratio, $r$ Correlation coefficient, sd standard deviation, UPDRS Unified Parkinson's Disease Rating Scale Variables included in multivariable analysis:

${ }^{a} \mathrm{Age}$, age of onset, gender, education level, scores of speech, facial expression, tremor, rigidity, bradykinesia and axial impairment in the UPDRS, total HAMD and HAMA scores, presence of sleep/ fatigue, perceptual problems/hallucinations, attention/memory, gastrointestinal domains from NMSS

${ }^{\mathrm{b}}$ History of BPH, age, education, depression, alpha-blocker, transitional zone volume of prostate

'Age, ethnicity, obesity, urban status (vs rural)

${ }^{\mathrm{d}}$ Age, ethnicity, hypertension, lower limb oedema, history of urinary incontinence, urban status (vs rural)

risk for bias in the measurement of exposure. Except for one study [21], no studies published information on blinding of outcome assessments or incomplete data. Although no studies referenced a published protocol with pre-defined outcomes, expected outcomes were reported in the results section of all 8 studies.

\section{Discussion \\ Summary of evidence}

To date, only 8 cross-sectional studies involving older populations, patients with $\mathrm{PD}$, or patients with $\mathrm{AD}$ have assessed the association between cognitive dysfunction and nocturia. The overall risk of bias of these studies was unclear. All 6 studies that identified a statistically significant association between nocturnal voiding frequency and cognitive dysfunction did so in the same direction [11, 17, 18, 21-23]. This association was shown to be independent in 2 studies. Accordingly, current literature suggests that a lower cognitive function is associated with a higher risk of nocturia, although more research is indeed needed to further elucidate the relationship between cognitive dysfunction and nocturia.

Although several studies have found a significant association between nocturia and cognitive dysfunction, the clinical relevance of these associations must be questioned.

\section{Strengths and weaknesses}

This systematic review is the first on the topic of cognitive dysfunction and nocturia. We identified studies which included nearly 4500 older patients in total.

However, the included study populations were heterogeneous, and varied in the means by which potential confounding factors were assessed. Indeed, age, sleep disorders, cardio-metabolic and central nervous system diseases are the main confounding factors in the relationship between cognitive disorders and nocturia (Fig. 3). If age is considered in each study including a multivariable analysis, only Zhang et al. (2016) have considered sleep disorders, cardio-metabolic diseases were partially considered in the study by Burgio et al. (2010) 


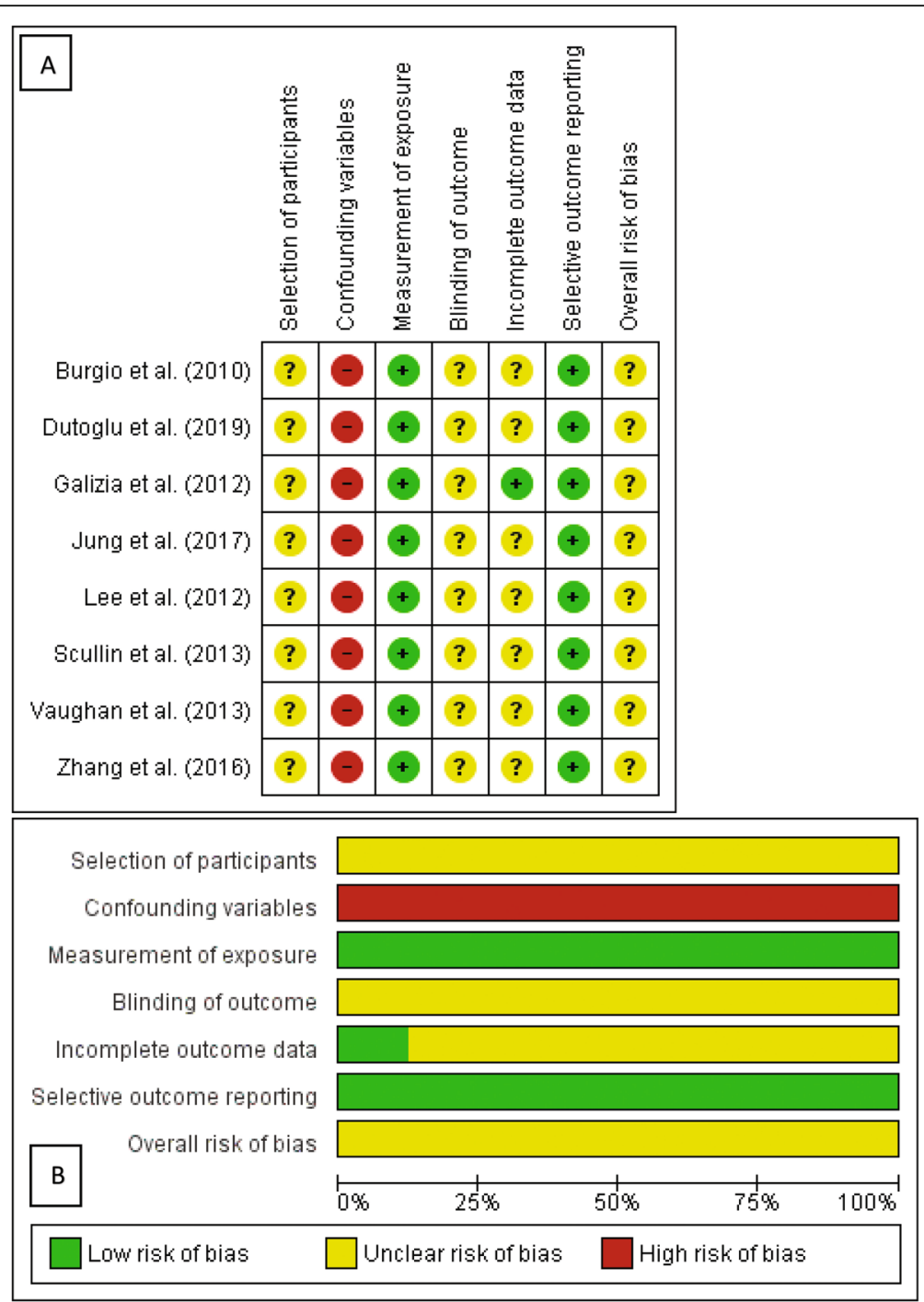

Fig. 2 Risk of bias in included studies. 2A. Risk of bias summary: review authors' judgements about each risk of bias item for each included study. 2B. Risk of bias graph: review authors' judgements about each risk of bias item presented as percentages across all included studies.? unclear risk of bias; -: high risk of bias; +: low risk of bias

and neurological diseases were ignored if we exclude the study in PD patients [18]. Moreover, the definition and assessment of nocturia (e.g., self-reported voiding frequency vs. symptom questionnaire data) varied across studies, which was consistent with a previous study [25]. At the time of publication, none of the studies included in this review used the exact terminology recommended by the International Continence Society, which states that each void is preceded and followed by sleep or the intention to sleep $[2,26]$. Nevertheless, several studies used the clinically significant threshold of two or more nocturnal voids [17, 20-23]. In addition, none of the studies assessed nocturia on frequency volume charts, but only on validated questionnaires or by history taking. This may have led to a risk of misclassification bias. Indeed, it has been shown that nocturia prevalence is overestimated when using questionnaires [27, 28]. Misestimating (over- or under-estimating) nocturnal voiding frequency to a greater extent in patients with cognitive dysfunction compared to those without could lead to this bias. Regarding cognitive dysfunction, the MMSE, was used in most of the included studies. It is a short, patient-friendly instrument, but may be influenced by educational attainment and age. These limitations, coupled with the relatively small number of studies which met the criteria for inclusion, precluded quantitative synthesis of study results.

Although several studies have found a significant association between nocturia and cognitive dysfunction, the clinical relevance of these associations must be questioned. While it is difficult to estimate for some studies, it appears to have been observed in others. For example, 


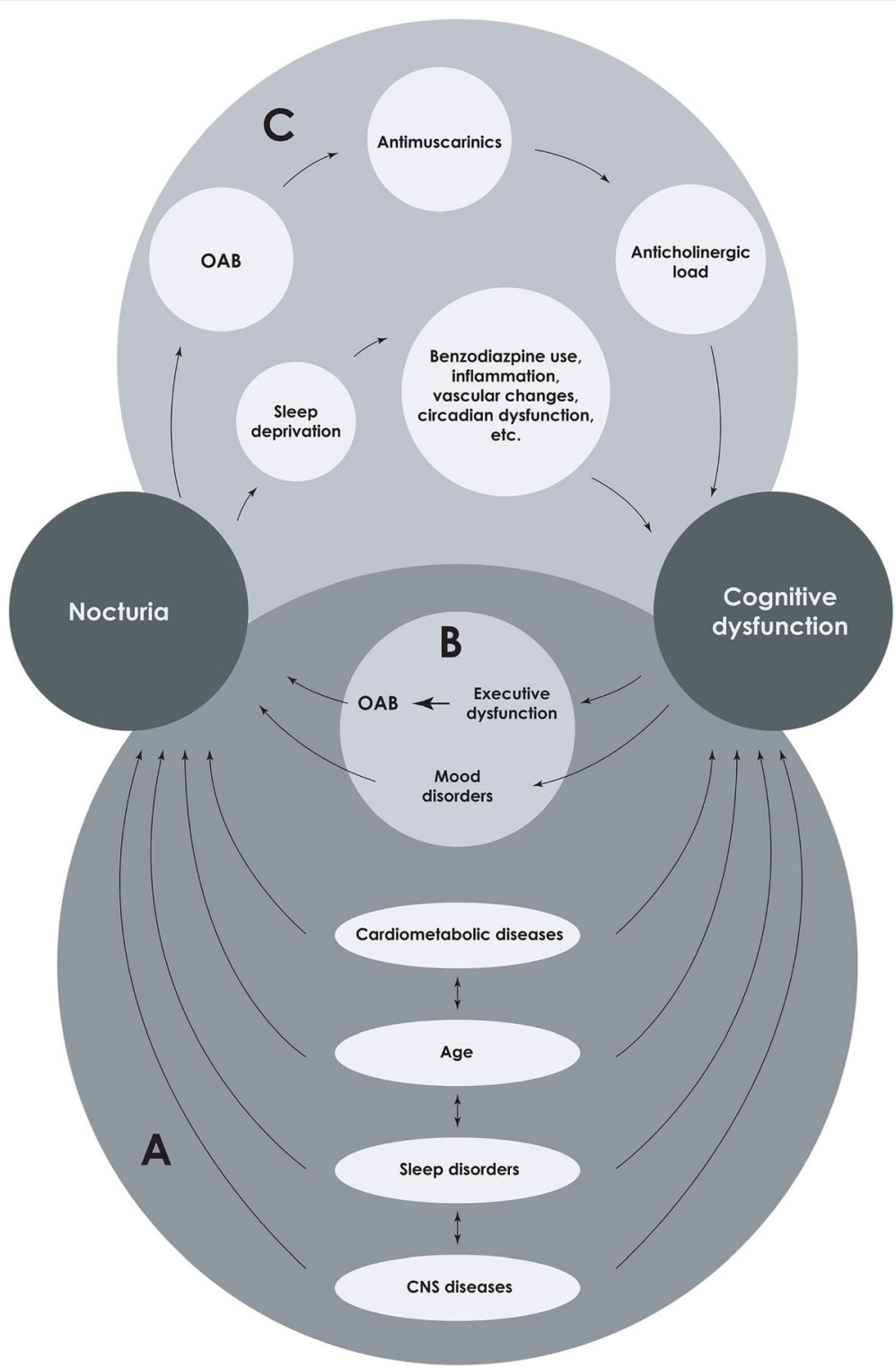

Fig. 3 Hypotheses for the association between cognitive dysfunction and nocturia. CNS: central nervous system; OAB: overactive bladder.

in the study by Lee et al. (2012), the observed difference in MMSE between patients with nocturia and those without nocturia was 1.5 points, which is considered clinically significant [29].

\section{Explanatory hypotheses}

The fact that only cross-sectional studies met the criteria for inclusion in this systematic review precludes identification of the precise cause-and-effect relationship between cognitive dysfunction and nocturia. Nevertheless, several non-mutually exclusive hypotheses may explain this association (Fig. 3).

Cognitive dysfunction and nocturia share many of the same risk factors (Part (a) of Fig. 3) including central nervous system pathologies [30], altered circadian rhythms of key hormones [15, 31,32], reduction in sex hormones [33, 34], sleep disorders [15, 34], comorbidities $[13,34]$, polypharmacy and modifiable lifestyle factors $[13,34,35]$. Furthermore, cognitive dysfunction could give rise to nocturia (part (b) of Fig. 3), mainly through impaired executive function, which is associated with overactive bladder syndrome [11, 12], and decrease in physical activity [36]. These two manifestations are known causes of nocturia [3,37]. Conversely, nocturia could give rise to cognitive impairment (part (c) of Fig. 3). Antimuscarinic agents use, a first-line therapy in the management of overactive bladder, may contribute to cognitive dysfunction [38] through an increase of the 
anticholinergic load. Moreover, nocturia-induced sleep impairment might lead to cognitive decline [13], via factors such as benzodiazepine use [15].

\section{Conclusions}

Nocturia is a complex and multifactorial condition, which may be the result of a primary abnormality of the genitourinary tract or a symptom of an underlying medical condition. The current framework for evaluation and management of nocturia broadly divides nocturia into four distinct etiologies: excessive nocturnal urine production ("nocturnal polyuria"), excessive 24-h urine production ("global polyuria"), reduced bladder capacity (functional or extrinsic), and sleep disorders (primary or secondary). However, the cause-and-effect relationship between nocturia and cognitive dysfunction remains poorly understood, and this may fall into overlapping pathophysiologic phenotypes. Nevertheless, the findings from this review suggests that nocturia is associated with cognitive impairment, and this could have consequential impacts on clinical practice. Indeed, it could make it possible to further appropriate assessment of signs or symptoms of memory loss in patients with nocturia, or to systematically look for this bothersome symptom in patients with cognitive dysfunction.

\section{Supplementary information}

Supplementary information accompanies this paper at https://doi.org/10. 1186/s12877-020-01622-8.

Additional file 1. Electronic search strategy. Description of the electronic search strategy used to find articles on the different databases.

\section{Abbreviations}

AD: Alzheimer's disease; CDR: Clinical Dementia Rating; LUTS: Lower urinary tract symptoms; MMSE: Mini-Mental State Examination; PD: Parkinson's disease; PRISMA: Preferred Reporting Items for Systematic Reviews and MetaAnalyses; RCTs: Randomized controlled trials; RoBANS: Risk of Bias Assessment tool for Non-randomized Studies

\section{Acknowledgments}

We would like to thank Jibé Kuchly Webdesign for the realization of Figures.

\section{Authors' contributions}

All authors meet the criteria for authorship: 1) substantial contributions to conception and design (RH, TFM, CJ, VP, WB, SR, GR, KE), or acquisition of data (RH, TFM), or analysis and interpretation of data (RH, TFM); 2) drafting the article $(\mathrm{RH}, \mathrm{KE}, \mathrm{TFM})$ or revising it critically for important intellectual content (RH, TFM, CJ, VP, WB, SR, GR, KE); and 3) final approval of the version to be published (RH, TFM, CJ, VP, WB, SR, GR, KE).

\section{Funding}

$\mathrm{RH}$ reports grants from, Fonds de dotation Renaitre, Société Française de Médecine Physique et de Réadaptation with the institutional support of Merz Pharma France and Société Interdisciplinaire Francophone d'UroDynamique et de Pelvi Périnéologie. Authors independently conceptualized the design, methods, data collection, analysis and writing of the manuscript and grants did not influence the content.
Availability of data and materials

Data sharing is not applicable to this article as no datasets were generated or analysed during the current study.

Ethics approval and consent to participate

Not applicable.

\section{Consent for publication}

Not applicable.

\section{Competing interests}

The authors declare that they have no competing interests.

\section{Author details}

${ }^{1}$ Department of Urology, Ghent University Hospital, Corneel Heymanslaan 10, 9000 Ghent, Belgium. ${ }^{2}$ GRC 001 GREEN Neuro-Urology Research Group, Sorbonne Université Rothschild Academic Hospital AP-HP, F-75012 Paris, France. ${ }^{3}$ Department of Urology, SUNY Downstate Medical Center, Brooklyn, NY, USA. ${ }^{4}$ Medical School Paris Île-de-France Ouest Inserm U1179, Versailles Saint-Quentin University, Versailles, France. ${ }^{5}$ Department of Physical Medicine and Rehabilitation, Raymond-Poincaré Academic Hospital AP-HP, Garches, France. ${ }^{6}$ Department of Urology, Sorbonne Université Pitié-Salpêtrière Academic Hospital AP-HP, Paris, France. ${ }^{7}$ Faculty of Medicine, Dentistry \& Health Sciences, The University of Melbourne, Melbourne, Australia.

Received: 4 February 2020 Accepted: 18 June 2020

Published online: 06 July 2020

\section{References}

1. Andersson F, Anderson P, Holm-Larsen T, Piercy J, Everaert K, Holbrook T. Assessing the impact of nocturia on health-related quality-of-life and utility: results of an observational survey in adults. J Med Econ. 2016;19:1200-6.

2. Hashim H, Blanker MH, Drake MJ, Djurhuus JC, Meijlink J, Morris V, et al. International continence society (ICS) report on the terminology for nocturia and nocturnal lower urinary tract function. Neurourol Urodyn. 2019;38(2):499-508.

3. Bosch JLHR, Weiss JP. The prevalence and causes of nocturia. J Urol. 2013; 189(1 Suppl):S86-92

4. Endeshaw YW, Schwartz AV, Stone $K$, Caserotti $P$, Harris T, Smagula S, et al. Nocturia, insomnia symptoms and mortality among older men: the health aging and body composition study. J Clin Sleep Med. 2016;12:789-96.

5. Bliwise DL, Foley DJ, Vitiello MV, Ansari FP, Ancoli-Israel S, Walsh JK. Nocturia and disturbed sleep in the elderly. Sleep Med. 2009;10:540-8.

6. Fung $\mathrm{CH}$, Vaughan $\mathrm{CP}$, Markland $\mathrm{AD}$, Huang AJ, Mitchell MN, Bliwise DL, et al. Nocturia is associated with poor sleep quality among older women in the study of osteoporotic fractures. J Am Geriatr Soc. 2017;65:2502-9.

7. Nakagawa H, Niu K, Hozawa A, Ikeda Y, Kaiho Y, Ohmori-Matsuda K, et al. Impact of nocturia on bone fracture and mortality in older individuals: a Japanese longitudinal cohort study. J Urol. 2010;184:1413-8.

8. Pesonen JS, Vernooij RWM, Cartwright R, Aoki Y, Agarwal A, Mangera A, et al. The Impact of Nocturia on Falls and Fractures: A Systematic Review and Meta-Analysis. J Urol. 2019;203(4):674-83.

9. Muir SW, Gopaul K, Montero Odasso MM. The role of cognitive impairment in fall risk among older adults: a systematic review and meta-analysis. Age Ageing. 2012;41:299-308

10. Akkoç Y, Bardak AN, Ersöz M, Yılmaz B, Yıldız N, Erhan B, et al. Post-stroke lower urinary system dysfunction and its relation with functional and mental status: a multicenter cross-sectional study. Top Stroke Rehabil. 2018; 26:136-41.

11. Jung HB, Choi DK, Lee SH, Cho ST, Na HR, Park MH. Correlation between overactive bladder symptom score and neuropsychological parameters in Alzheimer's disease patients with lower urinary tract symptom. Int Braz J Urol. 2017:43:256-63.

12. Sugimoto T, Yoshida M, Ono R, Murata S, Saji N, Niida S, et al. Frontal lobe function correlates with one-year incidence of urinary incontinence in elderly with Alzheimer disease. J Alzheimers Dis. 2017;56:567-74.

13. Baumgart M, Snyder HM, Carrillo MC, Fazio S, Kim H, Johns H. Summary of the evidence on modifiable risk factors for cognitive decline and dementia: a population-based perspective. Alzheimers Dement. 2015;11:718-26.

14. Capatina C, Paluzzi A, Mitchell R, Karavitaki N. Diabetes Insipidus after traumatic brain injury. J Clin Med. 2015;4:1448-62. 
15. Yaffe K, Falvey CM, Hoang T. Connections between sleep and cognition in older adults. Lancet Neurol. 2014;13:1017-28.

16. Moher D, Liberati A, Tetzlaff J, Altman DG, PRISMA group. Preferred reporting items for systematic reviews and meta-analyses: the PRISMA statement. PLoS Med. 2009;6:e1000097.

17. Dutoglu E, Soysal P, Smith L, Arik F, Kalan U, Kazancioglu RT, et al. Nocturia and its clinical implications in older women. Arch Gerontol Geriatr. 2019;85: 103917.

18. Zhang S, Ou R, Chen X, Yang J, Zhao B, Yuan X, et al. Correlative factors of cognitive dysfunction in PD patients: a cross-sectional study from Southwest China. Neurol Res. 2016;38:434-40.

19. Scullin MK, Sollinger AB, Land J, Wood-Siverio C, Zanders L, Lee R, et al. Sleep and impulsivity in Parkinson's disease. Parkinsonism Relat Disord. 2013;19:991-4

20. Vaughan CP, Juncos J, Trotti LM, Johnson TM, Bliwise DL. Nocturia and overnight Polysomnography in Parkinson disease. Neurourol Urodyn. 2013; 32. https://doi.org/10.1002/nau.22365.

21. Galizia G, Langellotto A, Cacciatore F, Mazzella F, Testa G, Della-Morte D, et al. Association between nocturia and falls-related long-term mortality risk in the elderly. J Am Med Dir Assoc. 2012;13:640-4.

22. Lee YJ, Jeong SJ, Byun SS, Lee JJ, Han JW, Kim KW. Prevalence and correlates of nocturia in community-dwelling older men: results from the korean longitudinal study on health and aging. Korean J Urol. 2012:53:263-7.

23. Burgio $\mathrm{KL}$, Johnson $\mathrm{TM}$, Goode PS, Markland $\mathrm{AD}$, Richter $\mathrm{HE}$, Roth $\mathrm{DL}$, et al. Prevalence and correlates of nocturia in community-dwelling older adults. J Am Geriatr Soc. 2010;58:861-6.

24. Kim SY, Park JE, Lee YJ, Seo H-J, Sheen S-S, Hahn S, et al. Testing a tool for assessing the risk of bias for nonrandomized studies showed moderate reliability and promising validity. J Clin Epidemiol. 2013;66:408-14.

25. Hofmeester I, Kollen BJ, Steffens MG, Bosch JLHR, Drake MJ, Weiss JP, et al. Impact of the international continence society (ICS) report on the standardisation of terminology in nocturia on the quality of reports on nocturia and nocturnal polyuria: a systematic review. BJU Int. 2015;115:520-36.

26. Van Kerrebroeck P, Abrams P, Chaikin D, Donovan J, Fonda D, Jackson S, et al. The standardization of terminology in nocturia: report from the standardization subcommittee of the international continence society. BJU Int. 2002;90:11-5.

27. van Haarst EP, Bosch JLHR, Heldeweg EA. The international prostate symptom score overestimates nocturia assessed by frequency-volume charts. J Urol. 2012:188:211-5.

28. Blanker MH, Bohnen AM, Groeneveld FP, Bernsen RM, Prins A, Ruud Bosch JL. Normal voiding patterns and determinants of increased diurnal and nocturnal voiding frequency in elderly men. J Urol. 2000;164:1201-5.

29. Andrews JS, Desai U, Kirson NY, Zichlin ML, Ball DE, Matthews BR. Disease severity and minimal clinically important differences in clinical outcome assessments for Alzheimer's disease clinical trials. Alzheimers Dement (N Y) 2019:5:354-63.

30. Haddad R, Denys P, Arlandis S, Giannantoni A, Popolo GD, Panicker JN, et al. Nocturia and nocturnal polyuria in neurological patients: from epidemiology to treatment. A systematic review of the literature. European urology. Focus. 2020;0. https://doi.org/10.1016/j.euf.2020.02.007.

31. Kim JW, Moon YT, Kim KD. Nocturia: the circadian voiding disorder. Investig Clin Urol. 2016:57:165-73.

32. Musiek ES, Holtzman DM. Mechanisms linking circadian clocks, sleep, and neurodegeneration. Science. 2016;354:1004-8.

33. Gurvich C, Hoy K, Thomas N, Kulkarni J. Sex differences and the influence of sex hormones on cognition through adulthood and the aging process. Brain Sci. 2018;8:163.

34. Yoshimura K. Correlates for nocturia: a review of epidemiological studies. Int J Urol. 2012;19:317-29.

35. Gray SL, Anderson ML, Dublin S, Hanlon JT, Hubbard R, Walker R, et al. Cumulative use of strong anticholinergics and incident dementia: a prospective cohort study. JAMA Intern Med. 2015;175:401-7.

36. De Cock A-M, Perkisas S, Verhoeven V, Vandewoude M, Fransen E, Remmen $R$. The impact of cognitive impairment on the physical ageing process. Aging Clin Exp Res. 2018;30:1297-306.

37. Everaert K, Hervé F, Bosch R, Dmochowski R, Drake M, Hashim H, et al. International continence society consensus on the diagnosis and treatment of nocturia. Neurourol Urodyn. 2019;38:478-98.
38. Kerdraon J, Robain G, Jeandel C, Mongiat Artus P, Gamé X, Fatton B, et al. Impact on cognitive function of anticholinergic drugs used for the treatment of overactive bladder in the elderly. Prog Urol. 2014;24:672-81.

\section{Publisher's Note}

Springer Nature remains neutral with regard to jurisdictional claims in published maps and institutional affiliations.

\section{Ready to submit your research? Choose BMC and benefit from:}

- fast, convenient online submission

- thorough peer review by experienced researchers in your field

- rapid publication on acceptance

- support for research data, including large and complex data types

- gold Open Access which fosters wider collaboration and increased citations

- maximum visibility for your research: over $100 \mathrm{M}$ website views per year

At BMC, research is always in progress.

Learn more biomedcentral.com/submissions 